\title{
Cystic cord lesions and neurological deterioration in spinal cord injury: operative considerations based on magnetic resonance imaging
}

\author{
M Silberstein MBBS, O Hennessy FRCR \\ Department of Radiology, Austin Hospital, Heidelberg, Victoria, Australia 3084.
}

In a retrospective review of 94 consecutive patients with past spinal cord injury referred for magnetic resonance imaging (MRI) for the evaluation of new neurological symptoms, $59 \%$ were found to have cystic spinal cord lesions. Twelve of these patients underwent surgical cyst drainage, half having presented with increased myelopathy, and half with ascent of the neurological level. All of the operated cysts were greater than $2 \mathrm{~cm}$ in diameter (mean $15.8 \mathrm{~cm}$ ), and 4 had areas of signal void indicating turbulent flow. All 12 patients had clinical improvement following surgery.

The future prospective use of MRI in patients with longstanding spinal cord injury may prove valuable in the identification of patients with syrinx formation, at risk of developing neurological deterioration, who may benefit from early cyst drainage. At present, however, the decision to operate on these patients should be based primarily on clinical criteria.

Key words: cystic cord lesions; spinal cord injury; magnetic resonance imaging.

\section{Introduction}

Post traumatic syringomyelia is a rare sequel of spinal cord injury but is important because of its association with delayed neurological deterioration, and the potential for treatment, resulting in arrest or reversal of signs and symptoms. ${ }^{1}$ The advent of magnetic resonance imaging (MRI) has resulted in a simple, noninvasive, method of making the diagnosis of idiopathic syringomyelia, ${ }^{2}$ and several reports have recently appeared in which MRI was used to demonstrate post traumatic syrinx formation, with subsequent surgical confirmation ${ }^{3,4}$ Gebarski et al ${ }^{3}$ had 7 patients with the preoperative diagnosis of syrinx, and subsequent surgery, and Quencher et $a l^{4}$ had 5 patients with a syrinx on MRI and subsequent surgery.

We retrospectively evaluated patients referred for MRI for delayed neurological deterioration following spinal trauma, who were found to have a syrinx and who were operated upon, to attempt to identify imaging criteria associated with improvement following surgery.

\section{Methods}

Between December 1987 and December 1990, 94 patients ( 74 males and 20 females) aged between 18 and 78 years (mean of 40 years) were referred for MRI to evaluate new symptoms following past spinal cord injury. Seventy-five patients had originally presented with a transverse clinical level at time of injury, 11 with central cord syndrome, and 8 with a Brown-Séquard syndrome. Fifty-seven patients had injuries to the cervical spinal cord, and 37 to the thoracic cord.

Patients included were admitted to the hospital spinal injuries unit at original presentation, with a single level deficit above the conus medullaris, and subsequent presentation to the unit with new symptoms developing following neurological stabilisation. Neurological status was classified according to Frankel et $a l^{5}$ (Table I), at time of neurological stabilisation and at time of presentation with new symptoms. The pattern of clinical presentation was classified as: increasing myelopathy - an alteration in 
Table I Frankel classification

\begin{tabular}{|c|c|}
\hline A & Complete motor and sensory loss \\
\hline B & $\begin{array}{l}\text { Complete motor loss but some sensation } \\
\text { preserved }\end{array}$ \\
\hline C & $\begin{array}{l}\text { Some motor power preserved, but of no } \\
\text { functional use }\end{array}$ \\
\hline $\mathrm{D}$ & $\begin{array}{l}\text { Useful motor power, including walking } \\
\text { with or without aids }\end{array}$ \\
\hline$E$ & Free of neurological symptoms \\
\hline
\end{tabular}

Frankel Grade; ascending neurological level; pain of recent onset; hyperhidrosis of recent onset; and increasing muscular spasms of recent onset. Presentation was between 4 months and 408 months from original injury (mean of 114 months), and MRI was performed on all patients within 3 weeks of presentation.

The MRI studies were obtained on a 0.3T resistive magnet (Fonar; B3000) with a spin-echo (SE) technique using 2 sagittal sequences and 2 axial sequences (TR/TE $=500 / 16$ for $\mathrm{T} 1$ weighted images and $2500 / 80$ for T2 weighted images), $5 \mathrm{~mm}$ slice thickness and $2 \mathrm{~mm}$ interslice gap.

Syrinx was defined as a very well defined area of CSF intensity on T1 weighted images. If a rim of hyperintensity was present in relation to the syrinx on $\mathrm{T} 2$ weighted images, and the cystic component was less than $5 \mathrm{~mm}$ in diameter, the lesion was classified as cystic myelomalacia, but if greater than $5 \mathrm{~mm}$ in diameter, it was classified as a syrinx, regardless of its rim.

In patients who subsequently underwent surgery, the MR images were reanalysed for the presence of any additional features such as syrinx size and signal characteristics. This was not done on patients who did not have surgery, as the films on some of these patients were not available for subsequent review.

\section{Results}

A syrinx was identified on MRI in $41 \%$ of patients, and an additional $15 \%$ were classified as having cystic myelomalacia. In patients with a syrinx (Fig 1), 41\% presented with increasing myelopathy, $38 \%$ with ascending neurological level, $10 \%$ with hyperhidrosis, $8 \%$ with pain, and $3 \%$ with increasing spasms. Increasing myelopathy was the most frequent form of presentation in patients with cystic myelomalacia $(57 \%)$, followed by ascending level and increasing spasms (14\% each).

The Frankel Grades for the patients with cystic spinal cord lesions, both at the time of neurological stabilisation, and at symptomatic presentation, are given in Table II. In patients with a syrinx, Grade A was found most often at the time of neurological stabilisation $(44 \%)$, with a further $26 \%$ of patients deteriorating to Grade A $(13 \%$ from $\mathrm{B}$, and $13 \%$ from $\mathrm{C}$ ) by the time of symptomatic presentation. Whereas $18 \%$ of patients who were subsequently found to have a syrinx were Grade D at time of neurological stabilisation, there were no patients in this category by the time of symptomatic presentation.

Of the patients found to have a syrinx on MRI, $12(31 \%)$ subsequently underwent surgery, whilst 2 other patients had surgical decompression of the spinal cord, due to an arachnoid cyst in one, and a large ossific spur in the other. The clinical and MRI details of the patients who underwent syrinx drainage are given in Table 3 . These patients presented with either increasing myelopathy or ascending level $(50 \%$ in each group). Of the 6 patients presenting with ascending level, 2 also had deterioration of Frankel Grade at physical examination. Whereas at the time of neurological stabilisation $42 \%$ of these patients were Grade $\mathrm{A}$ or $\mathrm{B}$, and $25 \%$ were Grade D, at symptomatic presentation, all were Grade A or B. Longitudinal syrinx extent on MRI ranged between $2 \mathrm{~cm}$ and $30 \mathrm{~cm}$ (mean $15.8 \mathrm{~cm}$ ), with 4 of the patients having areas of signal void within the syrinx cavity on the T2 weighted images indicating turbulent flow of syrinx contents (Figs 2 and 3). All 12 patients underwent syringocisternal, syringopleural or syringoperitoneal shunting, with clinical improvement in every patient. Patients presenting with ascending level demonstrated descent of clinical level following shunting, and patients presenting with increasing myelopathy had a reduction in degree of impairment following shunting 
a

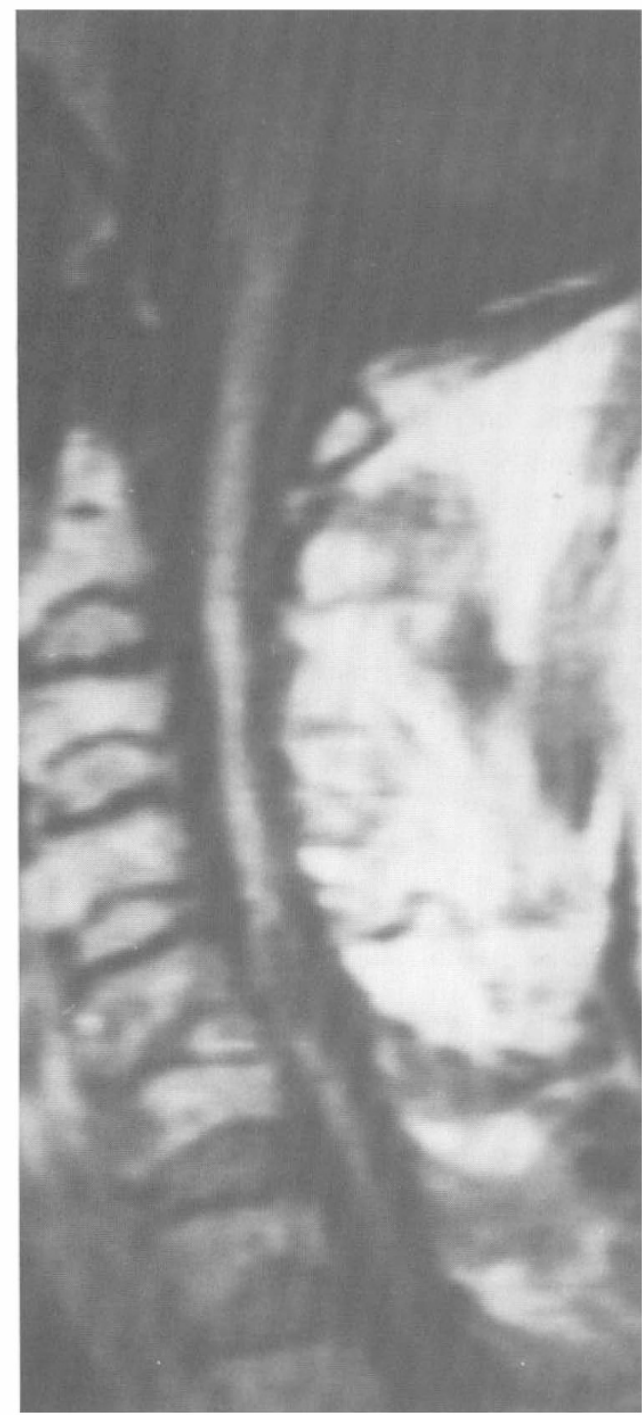

(Fig 4). The 2 patients with spinal cord compression presented with increasing myelopathy, and both improved following surgery.

\section{Discussion}

Previous descriptions of post traumatic syringomyelia have suggested that this is a rare sequel of spinal cord injury, with an incidence, based primarily on clinical features, of between $0.5 \%$ and $3.2 \%{ }^{6.7}$ b

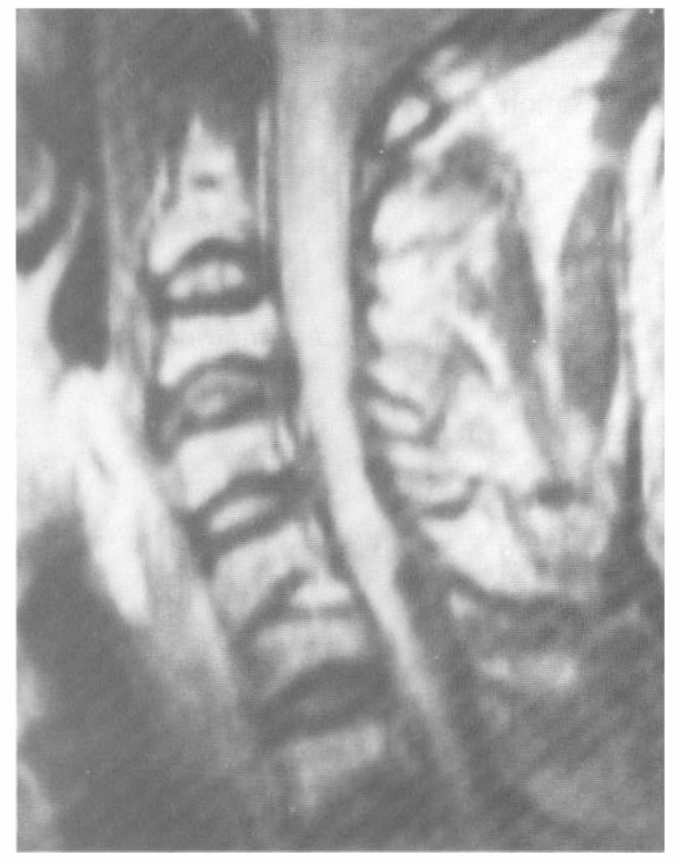

Figure 1 Small syrinx in a 52 year old male who developed increase in myelopathy ( $\mathrm{C}$ to $\mathrm{A}), 8$ years following a diving injury. (a) Sagittal T1 weighted image shows low signal syrinx above old burst fracture at C6. (b) T2 weighted image. The syrinx is isointense to CSF.

Only a limited number of series have described patients with neuroradiological confirmation of syrinx. Until recently, computed tomography has been the method of choice for diagnosis, and most reports have described patients identified with this technique. Lyons et $a l^{8}$ described 15 patients identified in this manner, and Rossier et al ${ }^{6}$ included 25 patients in their series, in whom a post traumatic syrinx was confirmed with either CT-myelography or air-myelography. In a series of 64 patients suspected of having a syrinx, Stevens et $a l^{9}$ described 29 patients 
Table II MRI findings related to Frankel Grades at neurological stabilisation and time of symptomatic presentation

\begin{tabular}{lccr}
\hline Stabilisation & Presentation & \multicolumn{2}{c}{$\begin{array}{c}\text { Cystic } \\
\text { myelomalacia }\end{array}$} \\
& & 5 & 17 \\
A & A & 2 & 5 \\
B & A & 1 & 3 \\
& B & 0 & 5 \\
C & A & 1 & 1 \\
& B & 0 & 1 \\
D & C & 0 & 0 \\
& A & 2 & 5 \\
& B & 3 & 2 \\
& C & 14 & 39 \\
\hline
\end{tabular}

with neuroradiological evidence of a syrinx and surgical confirmation, as well as another 11 patients in whom surgery was not performed.

Magnetic resonance imaging is now the method of choice for the diagnosis of post traumatic syrinx, as it is noninvasive and does not require hospital admission, ${ }^{3}$ However, relatively few numbers of cases have been described in the literature. In a series of 76 patients examined with MRI in spinal trauma of long standing, of whom only 14 presented with symptomatic deterioration, Yamashita et al ${ }^{10}$ identified 8 patients with a syrinx. Quencher et $a l^{4}$ described 7 patients with a post traumatic syrinx, including one patient in whom intraoperative ultrasonography refuted this diagnosis. Betz et al ${ }^{11}$ identified 13 patients with a post traumatic syrinx on MRI in a series of 43 patients examined in the chronic stages of spinal cord injury.

In this context, the 53 patients in our series with evidence of cystic lesions in the spinal cord following trauma represents a significant number. Unfortunately, we do not have data on the overall patient population to calculate the incidence of this complication, but nevertheless, the fact that $56 \%$ of patients investigated for late neurological deterioration following spinal cord injury were found to have a spinal cord cystic lesion is an important one.

Perhaps of even greater importance is the therapeutic significance of demonstrating a syrinx in these patients. Whilst only 12 of our patients had surgical drainage, all had operative confirmation of the MRI findings, and all improved following surgery. In the series of Stevens et al, ${ }^{9} 33$ patients sus-

Table III Characteristics of patients who underwent operative syrinx drainage

\begin{tabular}{|c|c|c|c|c|c|c|c|c|}
\hline \multirow{2}{*}{$\begin{array}{l}\text { Patient } \\
\text { number }\end{array}$} & \multirow[t]{2}{*}{ Age } & \multirow[t]{2}{*}{ Sex } & \multirow{2}{*}{$\begin{array}{l}\text { Clinical } \\
\text { present }\end{array}$} & \multicolumn{3}{|c|}{ Frankel grade } & \multirow{2}{*}{$\begin{array}{l}\text { Syrinx } \\
\text { length }\end{array}$} & \multirow{2}{*}{$\begin{array}{l}\text { Flow } \\
\text { void }\end{array}$} \\
\hline & & & & Init & MRI & Post & & \\
\hline 1 & 51 & $\mathrm{~F}$ & Asc lev & A & A & D & $2 \mathrm{~cm}$ & $Y$ \\
\hline 2 & 62 & M & Inc myel & $\mathrm{C}$ & A & B & $4 \mathrm{~cm}$ & $\mathrm{~N}$ \\
\hline 3 & 31 & M & Asc lev & A & A & A & $5 \mathrm{~cm}$ & $\mathrm{~N}$ \\
\hline 4 & 44 & $\mathrm{M}$ & Inc myel & $\mathrm{C}$ & A & $\mathrm{C}$ & $6 \mathrm{~cm}$ & $\mathrm{~N}$ \\
\hline 5 & 40 & M & Asc lev & B & A & B & $8 \mathrm{~cm}$ & $\mathrm{~N}$ \\
\hline 6 & 25 & M & Inc myel & $\mathrm{D}$ & B & $\mathrm{D}$ & $15 \mathrm{~cm}$ & $\mathrm{~N}$ \\
\hline 7 & 43 & M & Asc lev & A & A & A & $19 \mathrm{~cm}$ & $\mathrm{Y}$ \\
\hline 8 & 28 & M & Asc lev & $\mathrm{C}$ & A & B & $20 \mathrm{~cm}$ & $\mathrm{~N}$ \\
\hline 9 & 31 & $\mathrm{M}$ & Asc lev & $\mathrm{C}$ & A & $\mathrm{C}$ & $25 \mathrm{~cm}$ & $\mathrm{Y}$ \\
\hline 10 & 34 & M & Asc lev & A & A & A & $25 \mathrm{~cm}$ & $\mathrm{Y}$ \\
\hline 11 & 62 & $\mathrm{M}$ & Inc myel & $\mathrm{D}$ & B & $\mathrm{D}$ & $30 \mathrm{~cm}$ & $\mathrm{~N}$ \\
\hline 12 & 34 & $\mathrm{M}$ & Inc myel & $\mathrm{D}$ & B & $\mathrm{D}$ & $30 \mathrm{~cm}$ & $\mathrm{Y}$ \\
\hline
\end{tabular}

Asc lev $=$ Ascent in neurological level

Inc myel $=$ Increase in degree of myelopathy

Init $=$ Time of neurological stabilisation

MRI = Time of presentation for MRI

Post $=$ Time of maximal postoperative improvement

All patients had improvement in symptoms following operation. 
$\mathbf{a}$

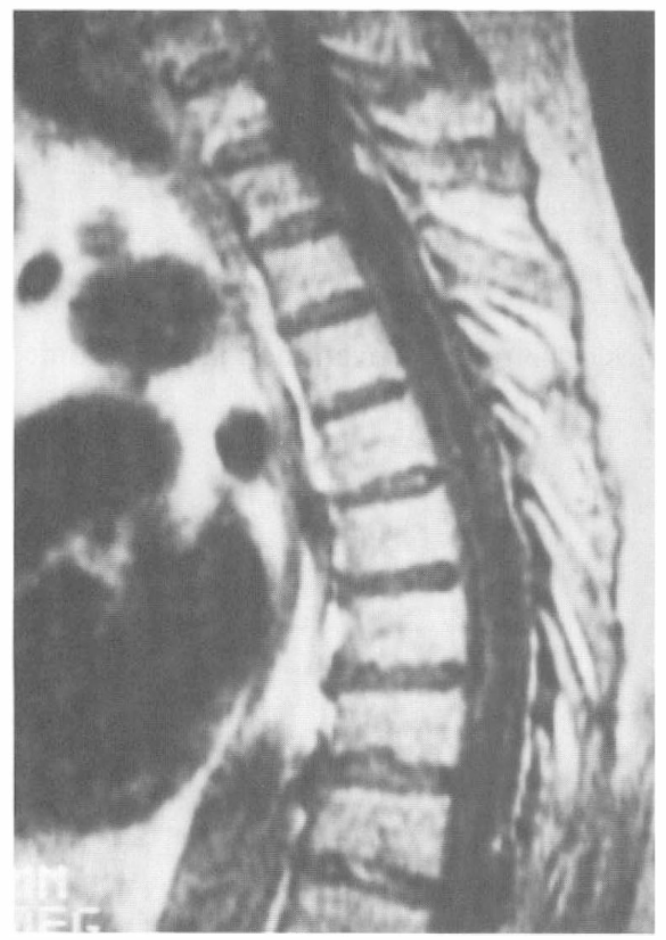

b

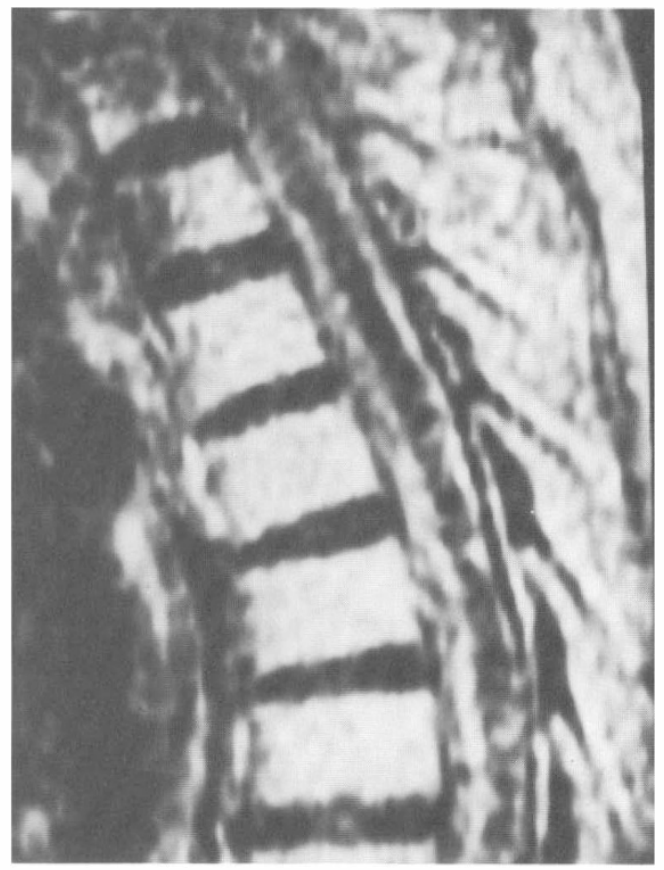

Figure 2 Extensive syrinx with intracystic flow void in a 62 year old male (Patient 11) who deteriorated from grade D to grade B 20 years following a fall resulting in incomplete T10 paraplegia. (a) Sagittal T1 weighted image shows extensive thoracic syrinx. (b) T2 weighted image. The syrinx cavity remains low in signal, indicating flow. There was improvement to grade $\mathrm{B}$ following cyst drainage.

pected of having a syrinx on the basis of myelography and CT, were operated upon, with 28 having a syrinx confirmed at operation. However, only $18(64 \%)$ improved following surgery. Williams et al ${ }^{12}$ described 10 patients with post traumatic syringomyelia of whom 5 had surgery, and 4 improved. In a series of 30 patients with cervical syringomyelia following trauma, 9 of 11 patients who had surgery improved ${ }^{6}$ and in a recent review, Williams ${ }^{1}$ described 24 patients with post traumatic syrinx, some of whom had MRI confirmation, who were operated upon, with 18 having some improvement. Lyons et $a l^{8}$ suggested that the most important reason for their good surgical results (20 of 21 patients improved) was the nature of the surgery, and, in particular, the use of syringo-cisternal shunting.
Our numbers are small, and the retrospective nature of our study prevents any conclusions based on statistical analysis, but certain facts are apparent. All of the patients were symptomatic, and 53 had evidence of cystic change in the spinal cord. At least 14 of these patients had cysts of less than $5 \mathrm{~mm}$ in diameter (included as cystic myelomalacia), yet even in this group there were 5 patients who had lost useful motor function from the time of neurological stabilisation. Although we did not have physical measurements of the longitudinal extents of syrinxes not operated upon, the majority of these were of $1 \mathrm{~cm}$ or under, yet all of these patients had developed new symptoms. Of the 27 patients with a syrinx who did not have surgery, $15 \%$ had lost useful motor function at time of symptomatic presentation. 


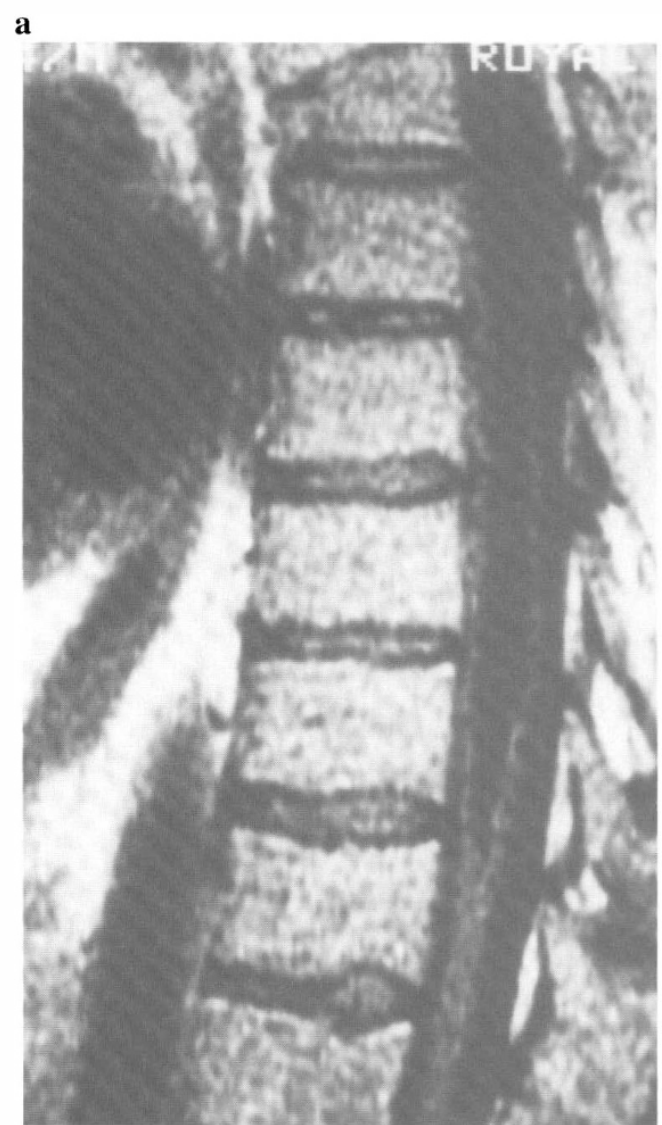

These results raise 2 important questions. First, when do patients become symptomatic from spinal cord cysts, and second, when should surgical drainage be performed? Our study, although deficient in that all cysts were not measured, is the first large series where any form of size measurements were obtained. Yet it fails to answer the question of when patients first become symptomatic from spinal cord cysts. Vernon et $\mathrm{al}^{7}$ suggested that as the cysts enlarge, symptoms develop due to compression of adjacent neural tissue. Following formation of a cavity in the spinal cord, which may be due to local ischaemia or release of cellular enzymes, ${ }^{3}$ expansion occurs by secretion of fluid from lining cells, ${ }^{12}$ and pressure changes transmitted from the subarachnoid space. ${ }^{13}$ Flow has been demonstrated within a syrinx cavity using standard spin-echo MRI techniques. ${ }^{14}$ In the former situation, b

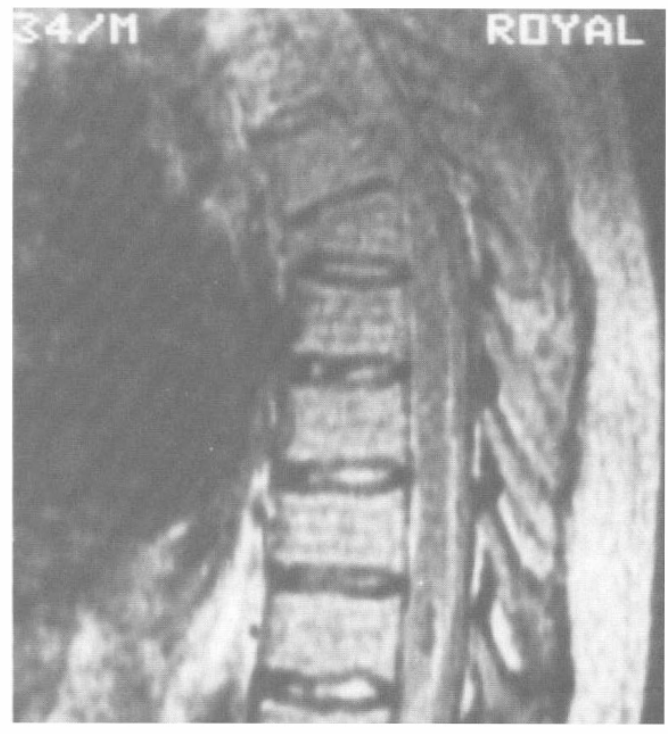

Figure 3 Long syrinx in a 34 year old male (Patient 12) who deteriorated from grade D to grade B 11 years following a motor vehicle injury resulting in incomplete T6 quadriplegia. (a) Sagittal T1 weighted image. The syrinx extends into the lower thoracic cord. (b) T2 weighted image. Much of the syrinx is isointense to CSF, but a short segment of flow void is present opposite T10. Improvement to grade D occurred following cyst drainage.

turbulent flow results in signal loss within the syrinx. We identified this sign in only 4 patients, almost certainly because all of our long TR images were obtained with flow compensation. This technique involved application of additional gradients during image acquisition to suppress motion, and reduce artifacts. ${ }^{15}$ In our images only first order gradient moment nulling was used, which suppresses signal loss from flow of constant velocity only. The 4 patients in whom a signal void was detected despite flow compensation, probably had significant turbulence or pulsatility resulting in signal loss. The future use of newer, gradientecho, MR techniques may prove to be the best method of demonstrating flow within a syrinx cavity.

In our patients, surgical drainage of a syrinx of less than $2 \mathrm{~cm}$ was not attempted, despite the demonstration of cysts of this 


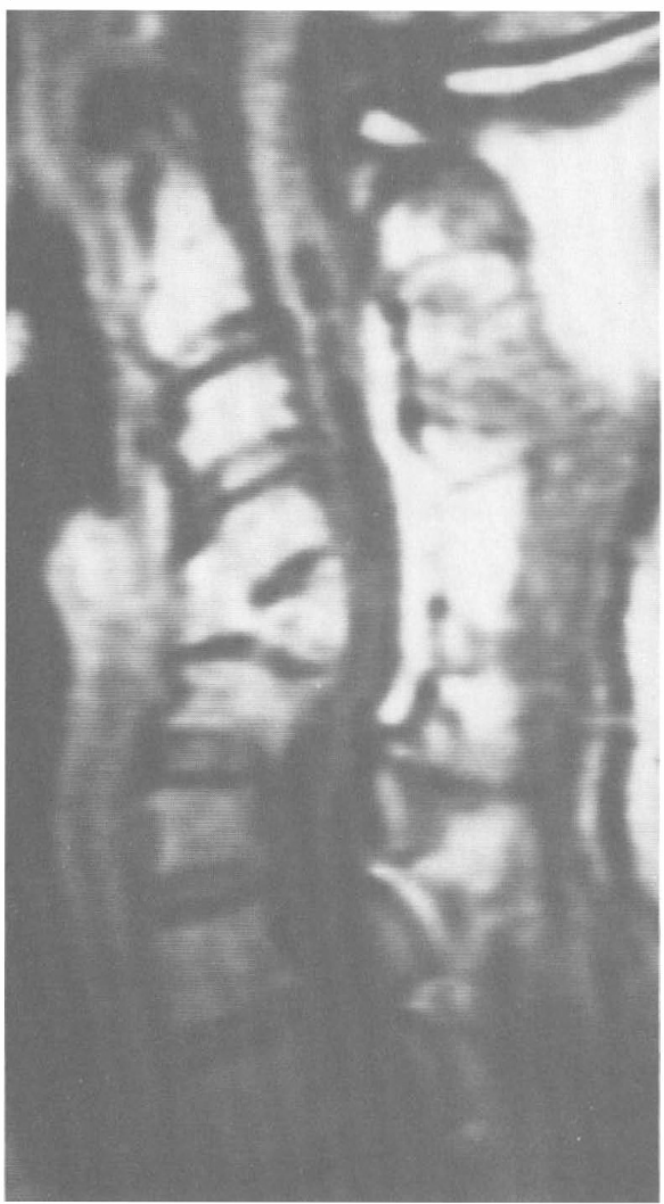

$\mathbf{b}$

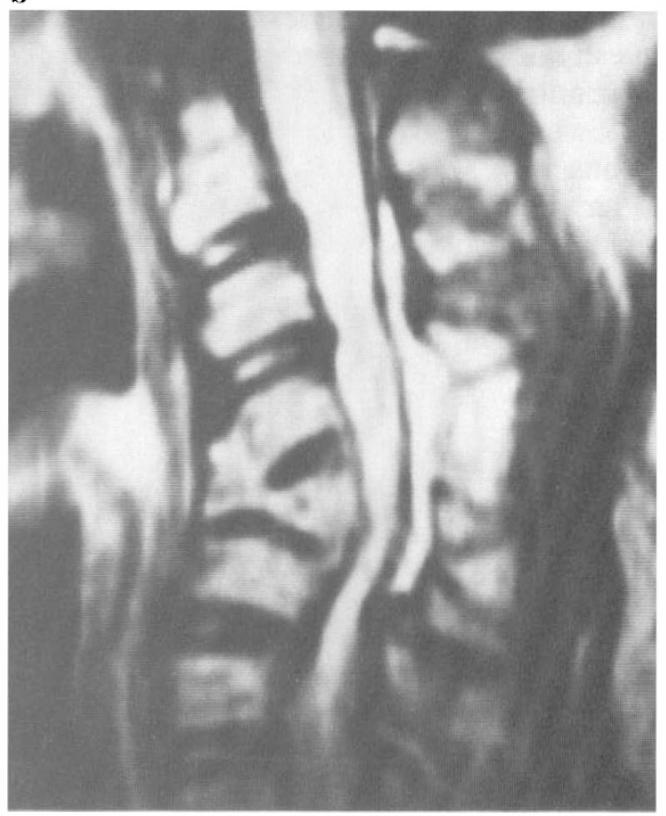

Figure 4 Longitudinal syrinx in a 40 year old male (Patient 5) who presented with ascent of neurological level from C5 to C3, and increased deficit from grade $\mathrm{B}$ to grade A, 17 years following a diving injury. (a) Sagittal T1 weighted image demonstrates syrinx from $\mathrm{C} 2$ to below level of vertebral injury at C5. (b) T2 weighted image. The syrinx is of high intensity, similar to CSF. Neurological improvement occurred following cyst drainage.

management to prevent enlargement to the stage where irreversible neurological damage has occurred. Indeed, Williams ${ }^{1}$ suggests that the shorter the time interval from injury to clinical presentation, the more urgent the need for operation.

Future identification of the role of turbulent flow and syrinx size in the induction of clinical symptoms in this group of patients will require prospective MRI and correlation of these parameters with the clinical findings. The results of this form of study may yield the answer to when these patients should undergo syrinx drainage to optimise their long term outlook, and minimise neurological deterioration. 


\section{Conclusion}

In a retrospective review of 94 patients investigated for delayed neurological deterioration following spinal cord injury, $56 \%$ were found to have cystic spinal cord lesions with MRI. Twelve of these patients underwent surgical syrinx drainage with clinical improvement. The routine use of MRI in this group of patients may, in the future, yield useful criteria for identifying patients who will benefit from syrinx drainage, but at present, once a syrinx has been confirmed with MRI, the decision to operate should be based primarily on the clinical context.

\section{Acknowledgement}

The authors thank Dr Douglas J Brown, Director of the Spinal Injuries Unit for his assistance.

\section{References}

1 Williams B (1990) Post-traumatic syringomyelia, an update. Paraplegia 28: 296-313.

2 Pojunas K, Williams AL, Daniels DL, Haughton VM (1984) Syringomyelia and hydromelia: magnetic resonance evaluation. 153: $679-683$.

3 Gebarski SS, Maynard FW, Gabrielsen TO, Knake JE, Latack JT, Hoff JT (1985) Posttraumatic progressive myelopathy. Radiology 157: 379-385.

4 Quencer RM, Sheldon JJ, Donovan Post JM, P Diaz RD, Montalvo BM, Green BA (1986) Magnetic resonance imaging of the chronically injured spinal cord. AJNR 7: 457-464.

5 Frankel HL, Hancock GO, Hyslop G, Melzak J, Michaelis LS, Ungar GH (1969) The value of postural reduction in the management of closed injuries of the spine with paraplegia and tetraplegia. Part I. Paraplegia 7: 179-192.

6 Rossier AB, Foo D, Shillito J, Dryo FM (1985) Posttraumatic cervical syringomyelia. Brain 108: 439-461.

7 Vernon JD, Silver JR, Ohry A (1982) Post-traumatic syringomyelia. Paraplegia 19: 89-95.

8 Lyons BM, Brown DJ, Calvert JM, Woodward JM, Wriedt CHR (1987) The diagnosis and management of post-traumatic syringomyelia. Paraplegia 25: 340-350.

9 Stevens JM, Olney JS, Kendall BE (1985) Post-traumatic cystic and non-cystic myelopathy. Neuroradiology 27: 48-56.

10 Yamashita Y, Takahashi M, Matsuno Y, Sakamato Y, Oguni T, Sakae T (1990) Chronic injuries of the spinal cord: assessment with MR imaging. Radiology 175: 849-854.

11 Betz RR, Gelman AJ, DeFilipp, Mesgarzadeh M, Clancy M, Steel HH (1987) Magnetic resonance imaging in the evaluation of spinal cord injured children and adolescents. Paraplegia 25: 92-99.

12 Barnett HJM, Jouse AT, Ball MJ (1973) Pathology and pathogenesis of progressive cystic myelopathy as a late sequel to spinal cord injury In: Barnett HJM. Foster JB, Hudgson P editors. Major Problems in Neurology. Syringomyelia. Vol 1. WB Saunders, London: 179-219.

13 Williams B, Terry AF, Francis Jones HW, McSweeney T (1981) Syringomyelia as a sequel to traumatic paraplegia. Paraplegia 19: 67-80.

14 Quencer RM (1988) The injured spinal cord. Evaluation with magnetic resonance and intraoperative sonography. Rad Clin North Am 26: 1025-1045.

15 Pattanay PM, Phillips JJ, Chiu LC, Lipcamon JD, Duerk JL, McNally JM (1987) Motion artifact suppression technique for MR imaging. J Comp Assist Tomogr 11: 369-377.

16 Watson N. Ascending cystic degeneration of the cord after spinal cord injury (1981) Paraplegia 19: 89-95. 